\title{
A Practical Study of the Thermal Performance of a Vacuum Tube for Solar Collector Using a Double-Sided Electronic Curtain with Nano- Fluid
}

\author{
Nagham A. Majeed*, Khalid F. Sultan ${ }^{\mathbb{D}}$, Hosham S. Anead $\mathbb{D}$ \\ Department of Electromechanical Engineering, University of Technology, Baghdad, Iraq. \\ *Corresponding author Email: eme.19.31 @ grad.uotechnology.edu.iq
}

\section{H I G H L I G H T S}

- Improving the performance of the evacuated tube solar collector by using the double- sided reflective electronic curtain.

- Improving the thermal properties of the evacuated tube solar collector by using two types of nanomaterials, aluminum and aluminum.

- The small size of the nanoparticles played an important role in improving the heat transfer.

- Increasing the rates of improving efficiency and useful heat gain by using the reflective electronic curtain.

\section{A R T I C L E IN F O}

\section{A B S T R A C T}

In this research, a practical study and appraisal of the thermal performance for the solar collector with vacuum tube has conducted Two types of nanomaterials (aluminum and aluminum oxide) have added to distilled water with nanoparticles diameters of $30 \mathrm{~nm}$ and $50 \mathrm{~nm}$ respectively. The nanomaterials were used in three several concentrations and three several flow rates which used as a working fluid in evacuated tube solar collector (ETSC) in order to increase the efficiency and beneficial thermal gain. An electronic double-sided reflective and absorbent electronic curtain were added to enhance the performance and control the temperature of the nanoscale. A clear improvement in efficiency was observed when using the reflective curtain that helped to speed up the Nano fluid heating and controlling the required temperature.

\author{
Handling editor: Muhsin J. Jweej \\ Keywords: \\ Evacuated Tube \\ Solar Reflector \\ Nano Fluid \\ Solar Collector
}

\section{Introduction}

Energy is a basic universe from the components of the universe, and the majority of energy comes from natural and unnatural sources. Therefore, energy is categorized into two main types: renewable energy, which is derived from natural sources, and non-renewable energy, which is derived from unnatural sources, but it was formed over time and as a result of a number of factors. [1]. Solar energy is the most important source of renewable energy and the most abundant in the world. Solar radiation can be used in several areas which is the most important of thermal energy production as well as the electricity generation. Therefore, it will meet a large proportion of the world's energy needs in the future especially it's a clean and environmentally friendly energy [2]. Solar energy is often converted either directly into electricity by photovoltaic cells and thermal energy through thermal collectors, or indirectly through its effects on rain, generating wind, or vegetation growth. In order to benefit from this abundant energy coming from the sun, people have begun to think of ways to collect this energy, benefit from it and exploit it in daily life [3]. Solar collectors are the nucleus in all types of solar energy devices, and it is a type of heat exchangers that convert solar energy into heat energy because it can absorb and convert the solar radiation to heat and transported by the working fluid and transportation medium such as air [4]. One of these solar collectors is the vacuum tube solar collector, which is considered one of the most efficient solar collectors because it is highly efficient in relation to the rest of the collectors, especially at low temperatures. It has a high thermal conductivity and the use of solar reflectors helps to concentrate the energy [5]. There are many previous studies that shed light on tube solar collectors. Alhabeeb et al. (2020) [6] 
used three types of solar reflectors included an aluminum foil, mirror and white paint. All these types were installed behind the tubes at distances $0.22,0.17$ and $0.12 \mathrm{~m}$. The results indicated that a flat mirror at a distance $0.17 \mathrm{~m}$ gave the best performance in improving the efficiency. Alkhaledi et al. [7] studied the thermal performance of the tubular solar collector using coating mirror reflectors that made by the 3M company. Reflectors were in four different shapes which are; flat shape, V-shape, once at an angle of 600 and again at an angle of 450 and the fourth shape was in a semicircle. The study reported that all types of reflectors provided a boost in thermal efficiency and the best one was the V-shaped inverter with an angle of 600 . Ghaderian et al. [8] used (Al2O3 +DW) as a basic fluid in tubular solar collector to study the impact of thermal efficiency. The performance of ETSC was compared with nano-fluid at a flow rate ranged from 20 to 60 liter per hour. The current study showed that the ultimate efficiency was $57.63 \%$ at a concentration of $0.06 \%$. Moreover, the flow rate of 60 liters per hour showed a greater improvement with increasing of the fractions of nanoparticle size and flow rate. Also, the results indicated that the nanoscale fluids can be used as basic fluids in the ETSC to absorb the heat from solar radiation and convert solar energy into thermal energy efficiently. Sultan [9] dealt with a practical study of the performance of the solar tube collector using metallic nanofluids such as copper $(\mathrm{Cu}(30 \mathrm{~nm})+\mathrm{Dw})$ and nonmetals such as titanium oxide $(\mathrm{TiO} 29(50 \mathrm{~nm})+\mathrm{Dw})$ with different granular sizes, different volume concentrations and different mass flow rates. The results showed that the efficiency of the solar collector using copper is greater than the efficiency of the collector using titanium oxide due to the granular size of copper in addition to the high conductivity of copper. Muslim [10] In a vacuum distiller, was built and implemented a fuzzy logic-based temperature controller. To increase the capability of generating a high concentrated bioethanol, the distiller is run at nearly vacuum. Temperature control was done by controlling AC voltage to heating elements due to the high heating power requirement. The efficiency of an Arduino-based Fuzzy Logic control strategy was compared to that of a PID controller. The Fuzzy logic controller has a better output in regulating the temperature while using a vacuum distiller, according to the results of the experiments. Bhowmik [11] introduced a modern technology to get better performance of the solar thermal collectors. The solar reflector is used to improve the collector's reflectivity. As a result, the reflector directs both direct and diffuse solar radiation toward the collector. The reflector was allowed to adjust its angle with daytime to increase the strength of incident radiation. The sun's energy was transformed into heat, which was then transferred to the collector fluid and water. Using the reflector, a prototype of a solar water heating system was developed, and the collector efficiency was improved by about $10 \%$. As a result, when compared to other systems, the current solar water heating systems have the best thermal efficiency. Dabra [12] indicated that different collector tilt angles from the horizontal existed for evacuated tube solar air collectors, with one inclined at $30^{\circ}$ and the other at $45^{\circ}$. Tilt angle had a substantial impact on the thermal efficiency of the evacuated tube solar air collector with or without reflector, according to the results of the experiments. Experiments also revealed that a $30^{\circ}$ tilt angle ETS air collector with reflector outperformed a $45^{\circ}$ tilt angle evacuated tube solar air collector with or without reflector in terms of thermal efficiency. This meant that raising the collector tilt angle had little effect on the thermo syphon within the evacuated tubes [13]. The effect of using an Al+Al2O3/distilled water hybrid Nano-fluid on the thermal efficiency of an evacuated tube solar collector with an inner cylindrical coil inside a vertical tank was investigated experimentally. With nanoparticle dimensions of $50 \mathrm{~nm}$, the volume fraction of nanoparticles was 1, 3 and $5 \%$. The efficiency of an evacuated tube solar collector (ETSC) using $\mathrm{Al}+\mathrm{Al} 2 \mathrm{O} 3$ hybrid Nano-fluid and water was compared to flow rates of 15, 30, and 45 1/hr.m2 inside the coil. The maximum solar collector effectiveness was found to be 24.89 percent with a mass flow rate of Nano-fluid of $45 \mathrm{l} / \mathrm{hr} . \mathrm{m} 2$ and a nanoparticle volume fraction of $5 \%$ vol. The findings revealed that $\mathrm{Al}+\mathrm{Al} 2 \mathrm{O} 3$ hybrid Nano-fluids could be used as working liquids in an ETSC to absorb heat from solar radiation and efficiently convert it into thermal energy. Mujawar and Shaikh [14] The heat pipe evacuated tube solar water heater was designed and built using circular heat pipes and CuO$\mathrm{H} 2 \mathrm{O}$ Nano-fluid as the working fluid. Experiments were performed from $11 \mathrm{a} . \mathrm{m}$. to 5.00 p.m. for different tilt angles of $25^{\circ}$, $30^{\circ}$, and $35^{\circ}$, as well as flow rates of $5 \mathrm{LPH}, 10 \mathrm{LPH}, 15 \mathrm{LPH}$, and $20 \mathrm{LPH}$. CuO/water nano-fluid has a higher thermal efficiency than traditional working fluid pure water in wickless evacuated tube heat pipe solar collectors. In the cases of pure water and $\mathrm{CuO} /$ water nano-fluid, increasing the tilt angle from $20^{\circ}$ to $30^{\circ}$ increased the solar collector instantaneous efficiency. As the tilt angle was raised above $30^{\circ}$ to $35^{\circ}$, the heat transfer rate decreased.

The main objective of this research is to improve the performance of the evacuated tubular solar collector by increasing its thermal efficiency and beneficial heat gain base on nanomaterials (aluminum and its oxide). The nano-fluid has added to the distilled water and considering it as a working fluid. The temperature of nano-fluid was controlled using double-sided reflective electronic curtain, where the reflective face was used to concentrate the solar radiation and utilized the hours of the day. While the absorbent face was used to control the temperature of the Nano fluid. At required temperature, the curtain on the absorbent side has opened to reduce the heat concentrated on the tubes.

\section{Evacuated tube solar collector (Etsc)}

The collector was made of 10 symmetrical evacuated glass pipes; each tube was concentric pipe that annular vacuum space between them to prevent the convection inside the glasses tube and warmth transfer conduction [15]. The nano-fluid circulates naturally between each tube and horizontal tank, the inner tank is formed of chrome steel material, the outer shell is formed of galvanized plate and it is insulated using foam as shown in Figure 1. Two types of nano-fluids (aluminum $\mathrm{Al}$ (30nm) and oxide aluminum $\mathrm{Al}_{2} \mathrm{O}_{3}(50 \mathrm{~nm})$ ) used with DW as working fluids. Table I shows the Nano-fluids properties. 

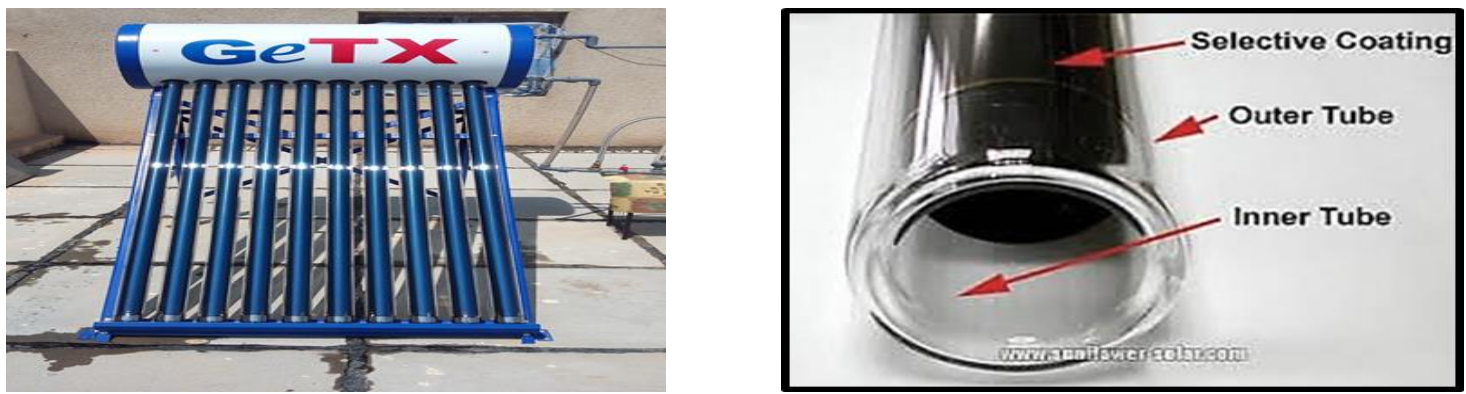

Figure 1: Evacuated tube solar collector without reflector

\section{Double-sided seflective electronic curtain system}

The reflective electronic curtain was used with the solar collector in this work. There are two main purposes for using this curtain, firstly, to reverse the dispersed solar radiation, redirect it and focus it towards the evacuated tubes that contain nano-fluid. Secondly, the absorption of solar radiation in the event that the required temperature of the nano-fluid is reached. In addition, Microcontroller (Arduino) was used to control the movement of the double-sided electronic curtain (reflector and absorbent) as shown in Figure 2.

\subsection{Equipment of electronic curtain}

The electronic curtain mainly consists of two parts as follows:

The mechanical part: which consists of the outer frame that is fixed to the solar collector structure by screws. This frame is used to fix the electronic curtain by means of two rollers from the top and bottom, a ball bearing used to facilitate the movement of the curtain, while flexible coupling transferring the movement from the motor to the upper roller to give it the required movement as well as rotating the curtain and absorbing the vibrations.

The curtain consists of three main components, the first is the basic material, which is a rubber material that used in the optical advertisements for installing the reflective and absorbent sides on it. While, the second component is the reflective face which is a reflective aluminum foil characterized by its great ability, unlike The solar radiation and its concentration, Finally, absorbent face is a black-colored adhesive due to the black color's ability to absorb radiation as it has a high absorption coefficient compared to the reflection and transmittance coefficient as shown in Figure 3.

Table 1: Nano-fluids properties

\begin{tabular}{|c|c|c|c|c|c|c|}
\hline Base fluid & $\operatorname{Pr}$ & $\begin{array}{c}\rho \\
(\mathrm{Kg} / \mathrm{m} 3)\end{array}$ & $\begin{array}{c}\mathrm{Cp} \\
(\mathrm{J} / \mathrm{kg} \mathrm{k})\end{array}$ & $\begin{array}{c}\mathrm{k} \\
(\mathrm{W} / \mathrm{m} \mathrm{k})\end{array}$ & $\begin{array}{c}\beta * 105 \\
(\mathrm{k}-1)\end{array}$ & $\begin{array}{l}\alpha * 105 \\
(\mathrm{~m} 2 / \mathrm{s})\end{array}$ \\
\hline Distilled water & $\begin{array}{l}6 . \\
2\end{array}$ & & 4179 & 0.613 & 21 & \\
\hline \multicolumn{7}{|c|}{ Nanoparticles } \\
\hline Aluminium (Al) & & 2707 & 896 & 236 & 2.4 & 973 \\
\hline Aluminium oxide (AL2O3) & & 2970 & 765 & 40 & 0.85 & 131.7 \\
\hline
\end{tabular}
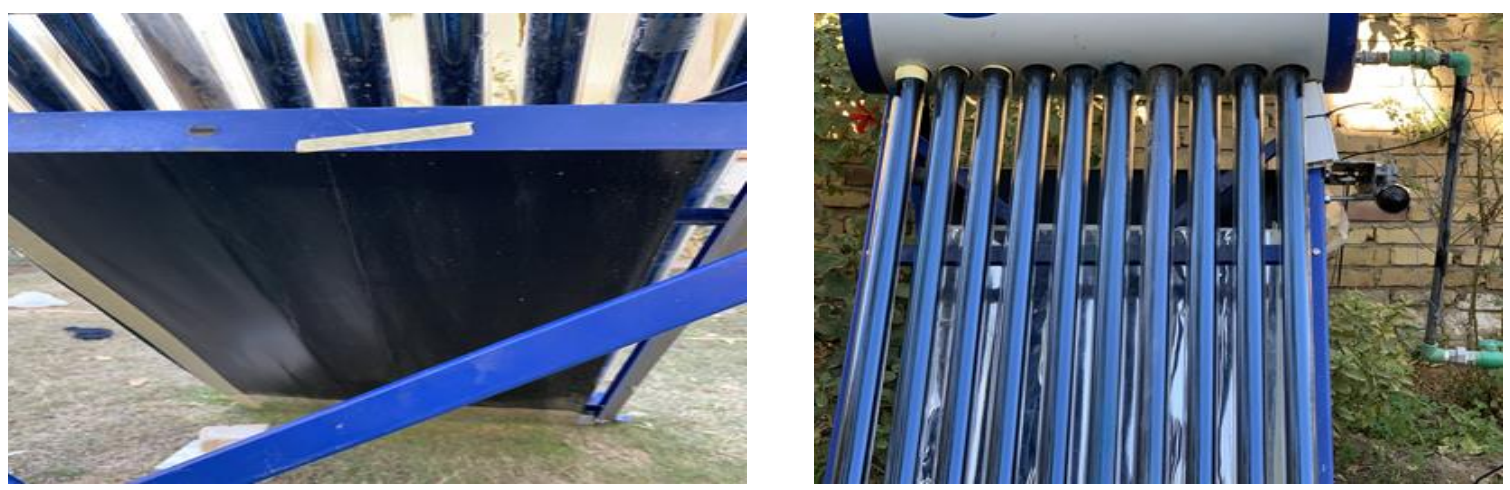

Figure 2: Electronic curtain 

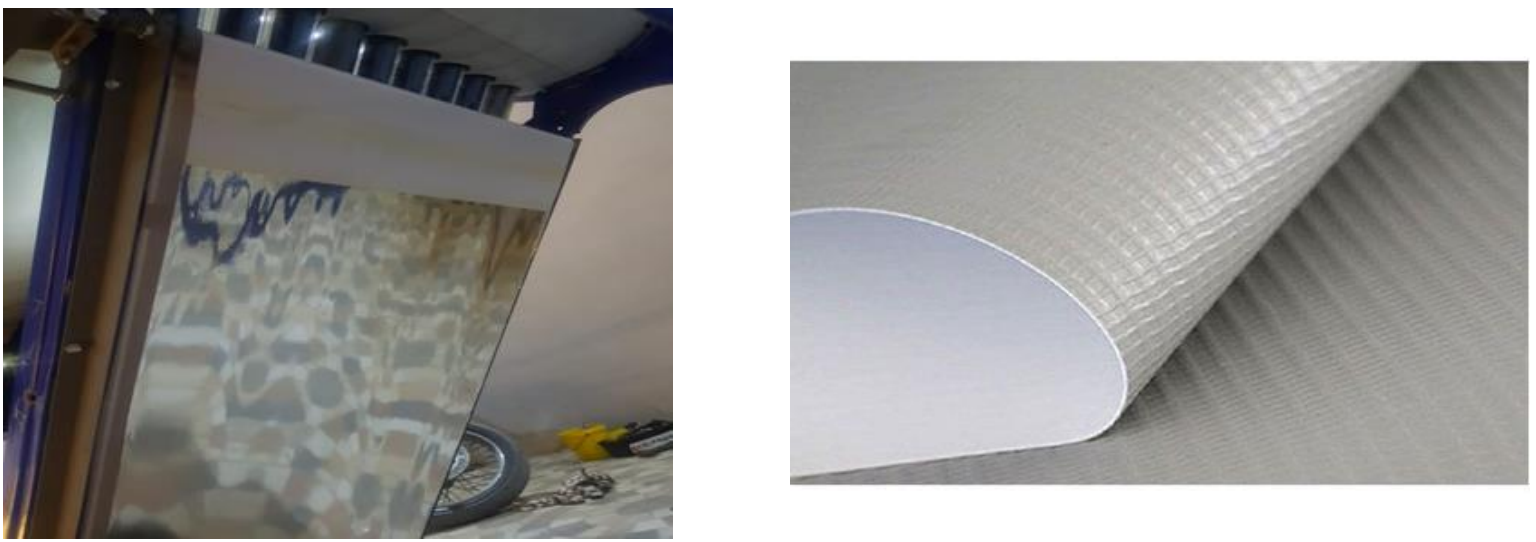

Figure 3: Main components of curtain

The electrical part: This part consists of several components, the first and most important one is the servo DC motor with $12 \mathrm{~V}, 70 \mathrm{rpm}$ and 3A with suitable gearbox to reduce the speed of motor. The motor was programmed to rotate the curtain between two faces (reflected, absorbing) according to the temperatures of nano-fluid. Arduino boards (Mega 2560) is used as a microcontroller with temperature sensor (Ds18B20), Line tracking sensor IR to reset the motor, Relay (JQC-3FF-S-Z) 5V as shown in Figures. 4 and 5.

\section{Experimental Procedures}

In this research, the solar collector consisted of ten evacuated tubes of air and connected to a main tank. Also, heat exchanger, pressure gauges and liquid flowmeter were used. Two types of nanomaterials were used: aluminum and aluminum oxide with a granular size of 30nm and 50nm, respectively. moreover, three different concentrations: 1,3 and ,5\% of each type of material were mixed with distilled water to become the main working fluid of the collector, then it pumped with three flow rates of 12, 24 and $36 \mathrm{~L} / \mathrm{M}$. The main valve has used for the purpose of pumping the required amount of nanoscale liquid through the collector. The test was carried out in two cases, the first case using the solar reflector, and the second case without using the solar reflector as shown in Figure 6.

The movement of the electronic curtain was controlled by programming the servo DC motor using Arduino board which was programmed in the $\mathrm{C}^{++}$language. The movement was relative to the temperature of the nanoscale fluid, where the temperature sensor was linked to the Arduino. When the temperature of the nano-fluid within $30^{\circ}$, the curtain opens totally, and the reflective face begins to move gradually towards the black face with increment of $10^{0}$ of the nanoscales until the required temperature is reached. Therefore, the curtain is completely open to the black face, and thus the work of the curtain will be with the hours of the day based on intensity of the solar radiation.
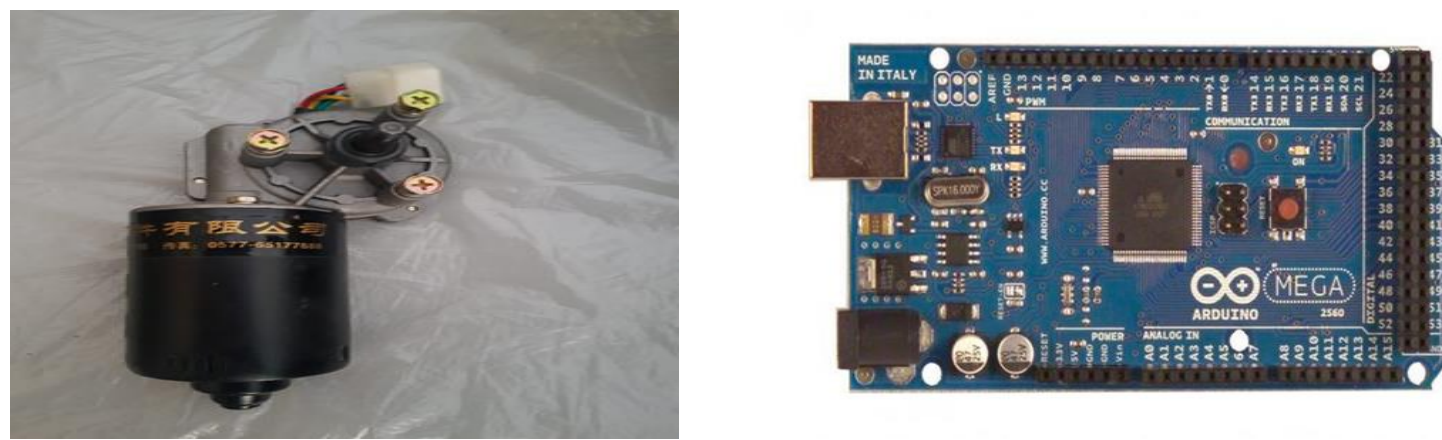

Figure 4: Servo DC motor and Arduino board 

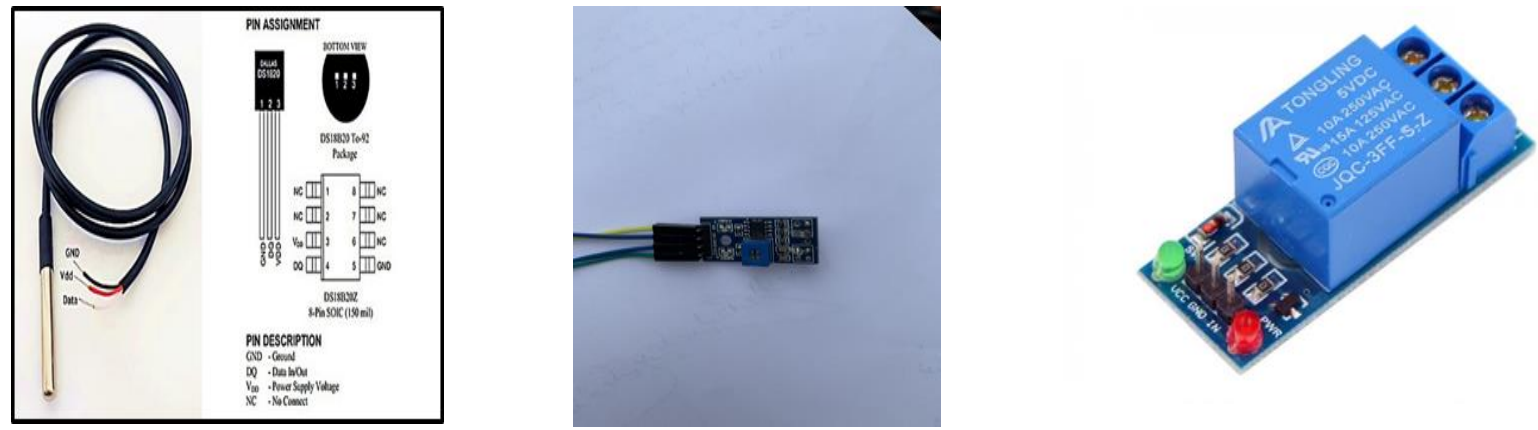

Figure 5: Temperature sensor, Line tracking sensor and Relay
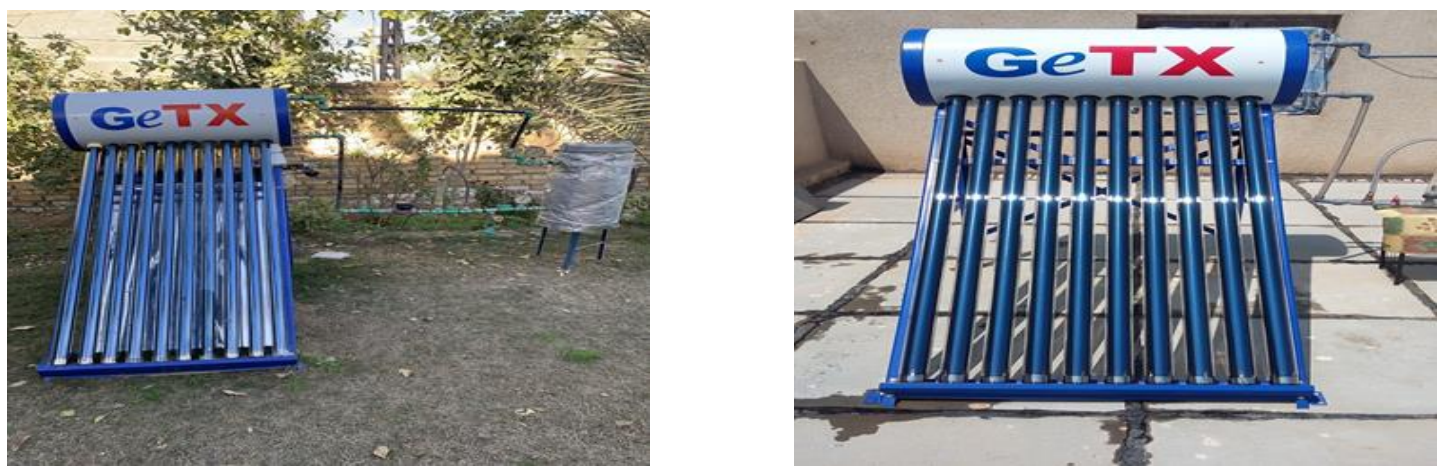

Figure 6: Solar collector with /without reflected curtain

\section{5. . Data Analysis and Validation}

The valuable heat energy, collector efficiency and difference of temperatures were calculated by Equations $(1-8)[16]$ as follows:

$$
\mathrm{Q}_{\mathrm{u}}=\mathrm{A}_{\mathrm{c}} \mathrm{F}_{\mathrm{R}}\left[\mathrm{I} \alpha \tau-\mathrm{U}_{\mathrm{L}}\left(\mathrm{T}_{\mathrm{f}}-\mathrm{T}_{\mathrm{a}}\right)\right]
$$

$\mathrm{Qu}$ is a useful heat energy.

When the heat energy changes to the thermal, energy for Dw in the tubes is:

$$
\mathrm{Q}=\dot{\mathrm{m}} \mathrm{Cp}\left(\mathrm{T}_{\mathrm{fo}}-\mathrm{T}_{\mathrm{f} i}\right)
$$

Then,

$$
\dot{\mathrm{m}} \mathrm{Cp}\left(\mathrm{T}_{\mathrm{fo}}-\mathrm{T}_{\mathrm{f} \mathrm{i}}\right)=\mathrm{A}_{\mathrm{c}} \mathrm{F}_{\mathrm{R}}\left[\mathrm{I} \alpha \tau-\mathrm{U}_{\mathrm{L}}\left(\mathrm{T}_{\mathrm{f}}-\mathrm{T}_{\mathrm{a}}\right)\right]
$$

Therefore,

$$
\left(\mathrm{T}_{\mathrm{f} \mathrm{o}}-\mathrm{T}_{\mathrm{f}}\right)=\left(\frac{\mathrm{A}_{\mathrm{c}} \mathrm{F}_{\mathrm{R}}}{\dot{\mathrm{m} \mathrm{Cp}}}\right)\left[\mathrm{I} \alpha \tau-\mathrm{U}_{\mathrm{L}}\left(\mathrm{T}_{\mathrm{f}}-\mathrm{T}_{\mathrm{a}}\right)\right]
$$

FR may be obtained from [17] as follows,

$$
F_{R}=\frac{\dot{m} C_{p}\left(T_{f o}-T_{f i}\right)}{A_{C}\left[I \alpha \tau-\left(T_{f}-T_{a}\right)\right]}
$$

The efficiency of collector can be defined as follow:

$$
\eta=\frac{Q_{u}}{A_{c} I}
$$

The result of substituting Eqs. (6) and (8) in Eq. (9) gives; 


$$
\eta=F_{R}\left[\alpha \tau-\frac{U_{L}\left(T_{f}-T_{a}\right)}{I}\right]
$$

Because $f R, \alpha \tau$ and UL are constant, then:

$$
\eta \alpha\left[\frac{\left(\mathrm{T}_{\mathrm{f}}-\mathrm{T}_{\mathrm{a}}\right)}{\mathrm{I}}\right]
$$

\section{Results and discussion}

The thermal performance of the solar collector was tested at different volumetric flow rates (12, 24 and $361 / \mathrm{min})$. The ambient temperature and wind speed were calculated at Babil Governorate at latitude of 32 north and longitude of 44 East on February 2, 2021 (a clear day) with an ambient temperature of $250 \mathrm{C}$ at 2:00 pm, while, the solar radiation reached to $598.55 \mathrm{w}$ / $\mathrm{m} 2$. The results showed that the percentages of improvement using Al with distilled water as a basic fluid are $20 \%, 22.8 \%$ and $26.92 \%$, while the ratios of $\mathrm{Al} 2 \mathrm{O} 3$ with distilled water as a basic fluid are $7.2 \%, 9.44 \%$ and $11.53 \%$. Also, its noted that the improvement rates in efficiency for the first type of nanofluid were higher than for the second type. This increasing in the improvement rates was due to two reasons: the first is the thermal properties and the size of the nanoparticles of the first type of nanomaterial which is better than the second type with different flow rates and concentrations. The second reason is solar reflector which is considering the major contributor for increasing the efficiency of the solar collector.

The results of both the efficiencies and the beneficial thermal gain of the solar collector for two types of nano-fluid (AL and AL2O3) were compared in two cases with and without reflective curtain as shown in Figures 7, 8, 9 and 10.

In Figures 7 and 9 that show the efficiency of the solar collector when using two different types of nanomaterials and with three different concentrations, its noticed that the efficiency improved significantly with increasing in the temperature of the nano-fluid because the efficiency is directly proportional to the temperature of the nano-fluid according to Eq. (8).

In Figures 8 and 10 which show the useful heat gain of the solar collector, the results showed that adding nanomaterials to distilled water gave a better thermal gain than when distilled water was used as a working fluid for the solar collector and showed the extent of increasing in the ability of the collector to collect the required amount of heat according to Eq. (1).

In general, adding the nanomaterial at a concentration of $5 \%$ gave the best results compared to the $1 \%$ of concentration. The performance was closed to the performance of distilled water. The percentage of improvement in efficiency can be seen in Table 2.

Table 2: Efficiency improvement ratios for Nano fluid

\begin{tabular}{cccc}
\hline Type & $\begin{array}{c}\text { Volume flow rate } \\
\text { L/min }\end{array}$ & $\begin{array}{c}\text { Concentration } \\
\text { Vol \% }\end{array}$ & $\begin{array}{c}\text { Enhancement } \\
\%\end{array}$ \\
\cline { 2 - 4 } $\mathbf{A l}(\mathbf{3 0 n m})+\mathbf{D w}$ & 12 & 5 & $20 \%$ \\
& 24 & 5 & $22.8 \%$ \\
& 36 & 5 & $26.92 \%$ \\
$\mathbf{A l}_{\mathbf{2}} \mathbf{O}_{\mathbf{3}}(\mathbf{5 0} \mathbf{n})+\mathbf{D w}$ & 12 & 5 & $7.2 \%$ \\
& 24 & 5 & $9.44 \%$ \\
$\mathbf{D w}$ & 36 & 5 & $11.53 \%$ \\
& 12 & 0 & $1.6 \%$ \\
& 24 & 0 & $2.36 \%$ \\
\hline
\end{tabular}



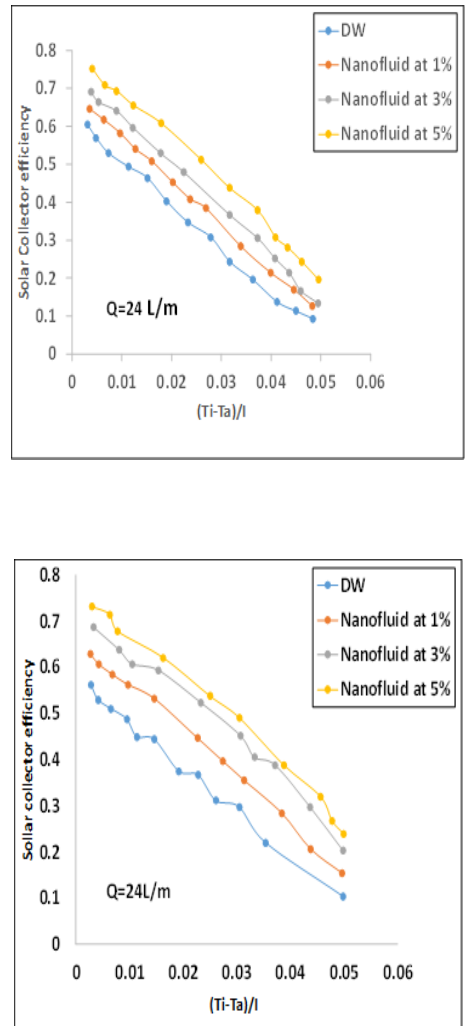
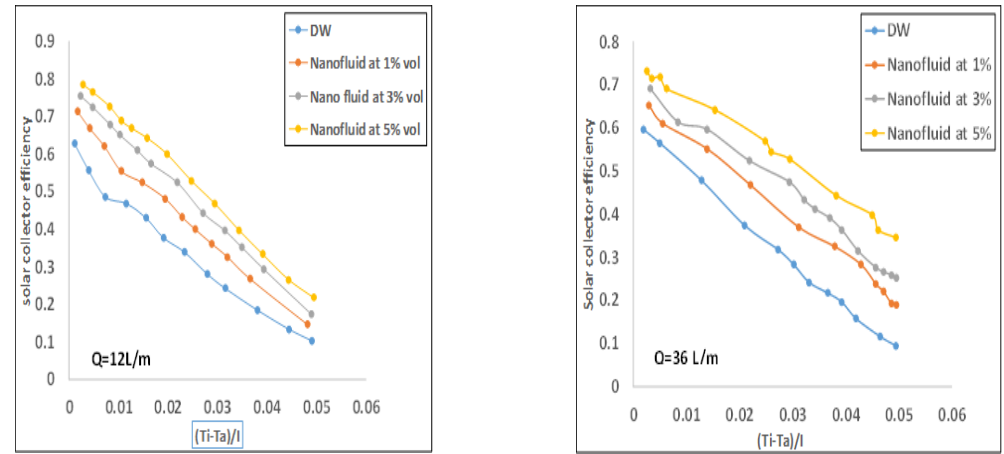

(A)
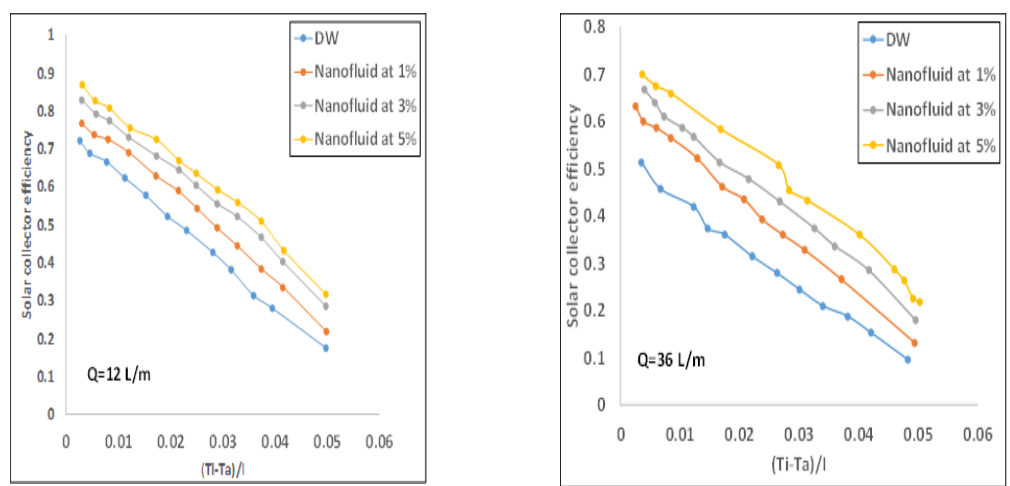

(B)

Figure 7: (A) Collector Efficiency for nano-particles (AL- DW) at different $\emptyset$ without reflector, (B) Collector Efficiency for nano-particles (AL- DW) at different $\varnothing$ with reflector
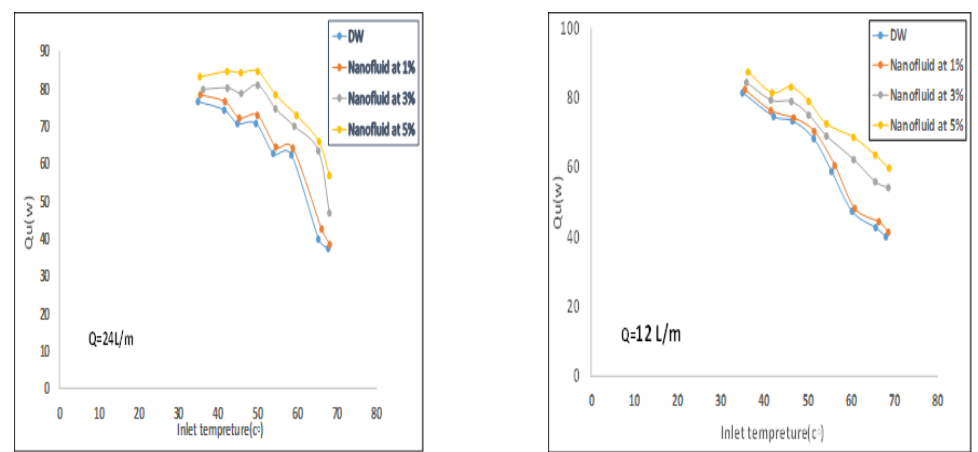

(A)

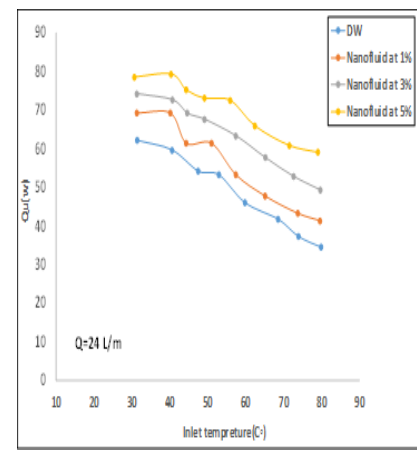

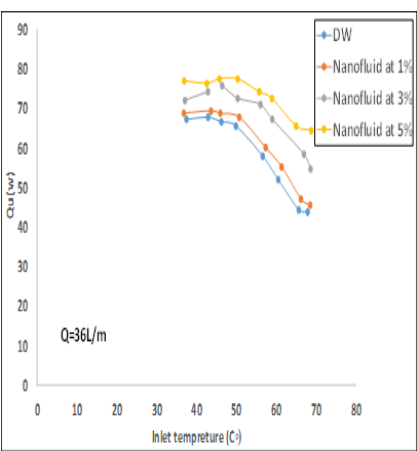

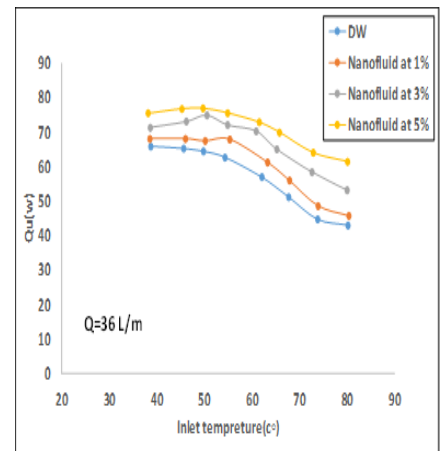

(B)

Figure 8: (A) Useful heat gain of collector for Nano particles (AL- DW) at different $\emptyset$ without reflector, (B) Useful heat gain of collector for nano-particles (AL- DW) at different $\varnothing$ with reflector 

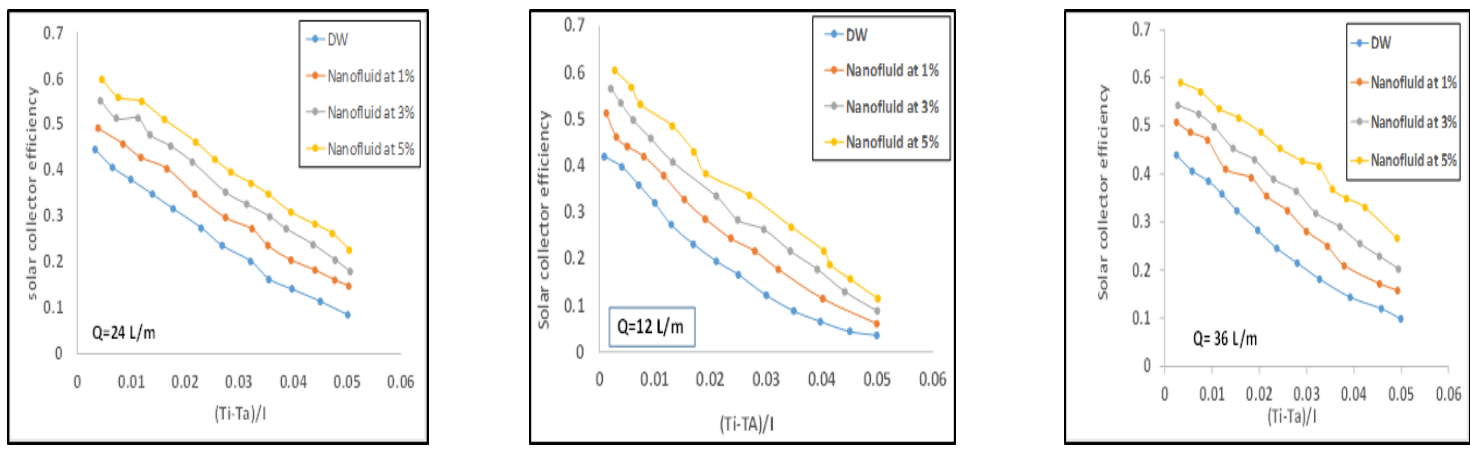

(A)
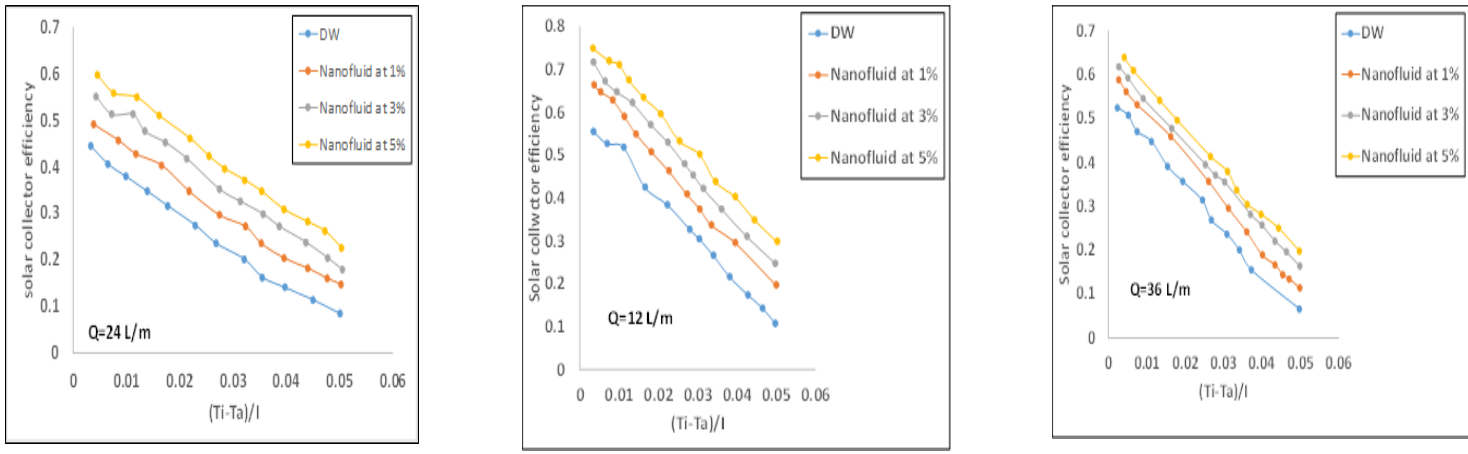

(B)

Figure 9: (A) Collector Efficiency for nano-particles $\left(\mathrm{AL}_{2} \mathrm{O}_{3}-\mathrm{DW}\right)$ at different $\emptyset$ without reflector,

(B) Collector Efficiency for nano-particles $\left(\mathrm{AL}_{2} \mathrm{O}_{3}\right.$ - DW) at different $\emptyset$ with reflector
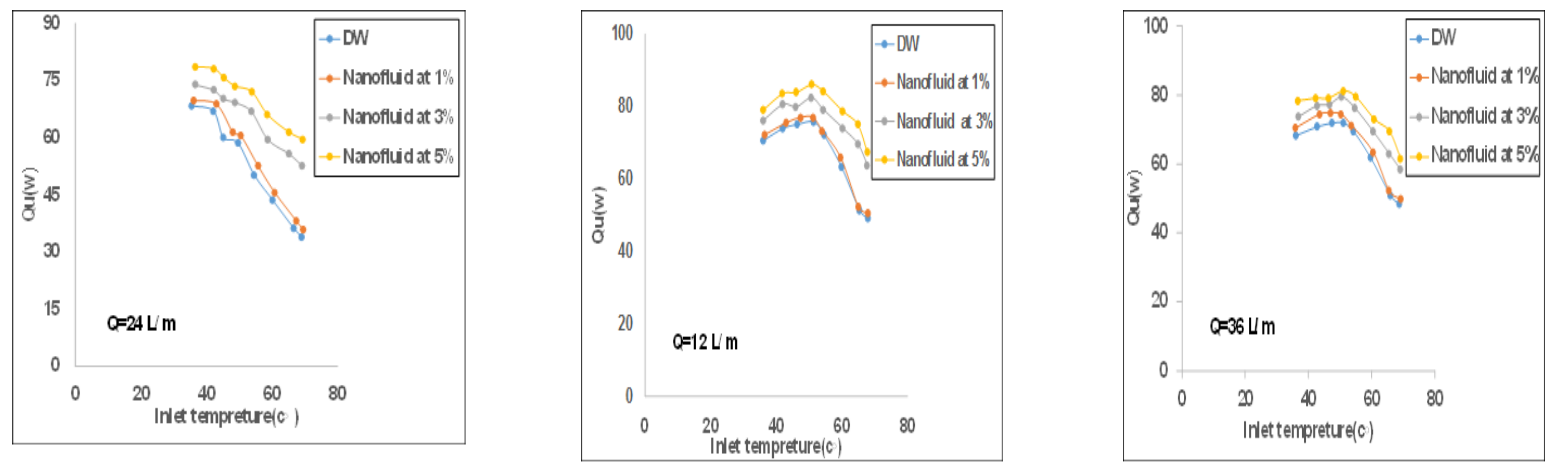

(A)
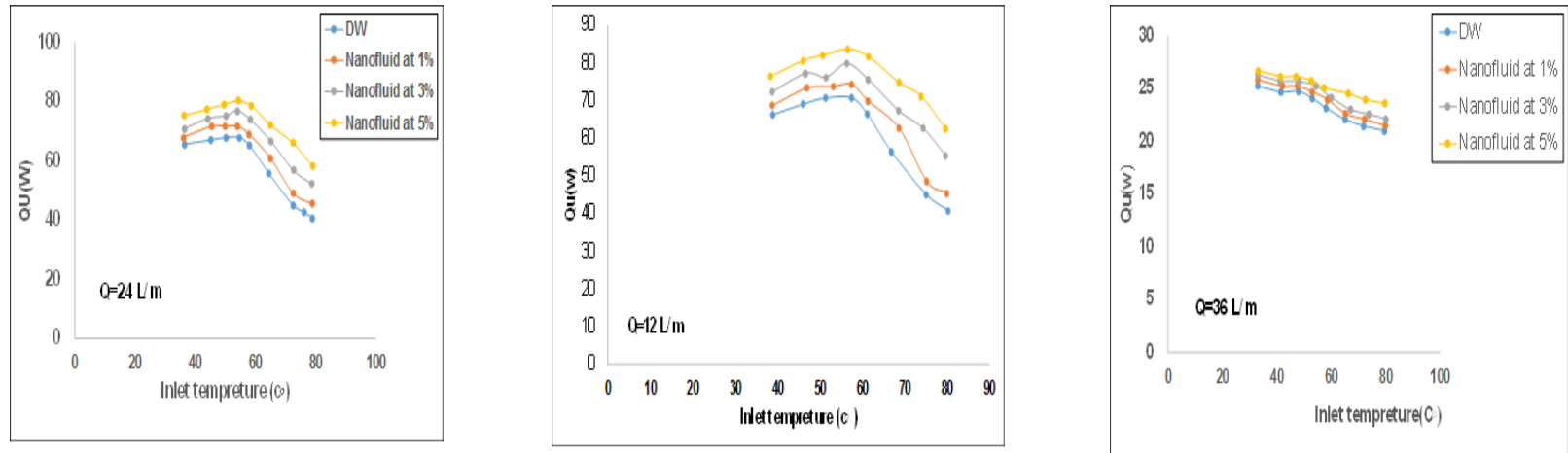

(B)

Figure 10: (A) Useful heat gain of collector for nano-particles $\left(\mathrm{AL}_{2} \mathrm{O}_{3}-\mathrm{DW}\right)$ at different $\emptyset$ without reflector, (B) Useful heat gain of collector for nano-particles $\left(\mathrm{AL}_{2} \mathrm{O}_{3}\right.$ - DW) at different $\varnothing$ with reflector 


\section{Conclusions}

In this work, many conclusions have been presented as follows:

1) Using of electronic curtain was a solution factor of improving the heat transfer as well as improvement in the performance of ETSC.

2) The efficiency improved significantly when using the nanoparticles metal, while when using oxide metal, the efficiency was lower due to the higher thermal conductivity of the nanomaterial.

3) Size and type of nanoparticles played a major role in optimizing the rate of heat transfer and enhancing the efficiency for solar collector evacuated.

4) The useful heat gain was improvement at using nanomaterial with distilled water at different concentration for two types of nano-fluid.

\section{Author contribution}

All authors contributed equally to this work.

\section{Funding}

This research received no specific grant from any funding agency in the public, commercial, or not-for-profit sectors.

\section{Data availability statement}

The data that support the findings of this study are available on request from the corresponding author.

\section{Conflicts of interest}

The authors declare that there is no conflict of interest.

\section{Reference}

[1] H. S. Anead, K. F. Sultan, S. A. Jabbar, Assessing the performance of the evacuated tube solar collector using smart curtain through (PSO based PID) controller and Nano fluid, Eng. Technol. J. 39 (2021) 137-152. http//: doi:10.30684/etj.v39i1A.1701

[2] V. Kumara, R.L. Shrivastava, S.P. Untawale Solar Energy: Review of Potential Green \& Clean Energy for Coastal and Offshore Applications, Aquatic Procedia 4 (2015) 473-480. https://doi.org/10.1016/j.aqpro.2015.02.062

[3] K. F. Sultan, H. T. Rishag, J. M. Fadhal, Augmentation of Heat Transfer for Spiral Coil Heat Exchanger in Solar Energy Systems by Using Nano fluids, The 5th International Scientific Conference for Nanotechnology and Advanced Materials and Their Applications ICNAMA 33 (2015) 1619-1634.

[4] H. B. Kulkarni, N. N. Shinde, S. P. Birder, V. P. Kulkarni, Review of Different Reflectors materials used for Concentrated Solar Energy Collectors, National conference on emerging technology on renewable energy, Guru Nanak Dev Engineering College, Bidar, Karnataka, (2014) 33-37.

[5] T. IGHIL, Razika, Nanomaterials in solar cells. Handbook of Nano electrochemistry, pp1-18, 2015.

[6] B. A. Alhabeeb, T. J. Kadhim, H. T. Hashim, H. N. Mohammed, Enhancement of the Thermal Efficiency of the Evacuated Tubes Solar Water Heater by Adding a Reflector, Int. Energy J., 20 (2020) 57-66.

[7] K. AlKhaledi, K.H. Means, S. Bendak, A.M. Arnold, J. Jones, Evacuated solar tube performance enhancement evaluation, J. Eng. Research, 5 (2017) 207-222.

[8] J. Ghaderian, N. Azwadi Che Sidik An experimental on the effect of Al2O3 /distilled water Nano fluid on the energy efficiency of evacuated tube solar collector, Int. J. Heat. Mass. Transf. 108 (2017) 972-987. https://doi.org/10.1016/j.ijheatmasstransfer.2016.12.10

[9] F. S. Khalid, Experimental evaluation of the thermal performance in the solar Nano fluid heating system by using Cupper and Titanium oxsed, Iraqi. J. Mech. Eng., 15 (2015).

[10] M. A. Muslim, G. D. Nusantoro, Fuzzy logic based temperature control of a vacuum distiller, Int J Appl Eng Res., ISSN0973-4562. 10 (2015) 38504-38508.

[11] H. Bhowmik, R. Amin, Efficiency improvement of flat plate collector using reflector, Energy Reports 3 (2017) 119-123. https://doi.org/10.1016/j.egyr.2017.08.002

[12] V. Dabra, L. Yadav, The effect of tilt angle on the performance of evacuated tube solar air collector: experimental analysis, Int. J. Eng. Sci. Technol. ISSN-2141-2839. 5 (2013). https://doi.org/10.4314/ijest.v5i4.9 
[13] A. M. Salman, H. S. Anead, K. F. Sultan, An experimental investigation on the effect of hybrid Nano fluid $(\mathrm{Al}+\mathrm{Al} 2 \mathrm{O} 3 /$ distilled water) on the thermal efficiency of evacuated tube solar collector, IOP Conference Series: Mater. Sci. Eng., 2019. https://doi.org/10.1088/1757-899X/745/1/012073

[14] N.H. Mujawar, S.M. Shaikh, Review paper on thermal performance investigation of evacuated tube heat pipe solar collector, Int. J. Eng. Sci. Res. Technol. ISSN:2277-9655, 2015.

[15] E, Zambolin, and D. Del Col, Experimental analysis of thermal performance of flat plate and evacuated tube solar collectors in stationary standard and daily conditions, Sol. Energy $84 \quad(2010) \quad 1382-1396$. https://doi.org/10.1016/j.solener.2010.04.020

[16] P. M. E., Koffi, H. Y., Andoh, P., Gbaha, Toure, S., G. Ado, Theoretical and experimental study of solar water heater with internal exchanger using thermo siphon system, Energy Convers. Manage., 49 (2008) 2279-2290. https://doi.org/10.1016/j.enconman.2008.01.032.

[17] S., Jaisankar, T. K., Radhakrishnan, K. N.Sheeba, Experimental studies on heat transfer and friction factor characteristics of forced circulation solar water heater system fitted with helical twisted tapes, Sol. Energy, 83 (2009) $1943-1952$. https://doi.org/10.1016/j.solener.2009.07.006. 